\title{
Botulinum toxin treatment of cranial-cervical dystonia, spasmodic dysphonia, other focal dystonias and hemifacial spasm
}

\author{
Joseph Jankovic, Kenneth Schwartz, Donald T Donovan
}

\begin{abstract}
In the past five years, 477 patients with various focal dystonias and hemifacial spasm received 3806 injections of botulinum $A$ toxin for relief of involunary spasms. A definite improvement with a global rating $\geqslant 2$ on a $0-4$ scale, was obtained in all 13 patients with spasmodic dysphonia, $94 \%$ of 70 patients with blepharospasm, $92 \%$ of 13 patients with hemifacial spasm, $90 \%$ of 195 patients with cervical dystonia, $77 \%$ of 22 patients with hand dystonia, $73 \%$ of 45 patients with oromandibular dystonia, and in $90 \%$ of 21 patients with other focal dystonia who had adequate follow up. While the average duration of maximum improvement lasted about 11 weeks after an injection (range seven weeks in patients with hand dystonia to 15 weeks in patients with hemifacial spasm), some patients benefited for over a year. Only $16 \%$ of the 941 treatment visits with follow up were not successful. Except for transient focal weakness, there were very few complications or systemic effects attributed to the injections. This study supports the conclusion that botulinum toxin injections are a safe and effective therapy for patients with focal dystonia and hemifacial spasm.
\end{abstract}

Dystonia is a neurological disorder characterised by involuntary, repetitive or sustained muscle contractions frequently causing twisting, squeezing or other movements, and abnormal postures. ${ }^{1}$ In most patients, no specific cause for the dystonia can be identified, hence the term primary or idiopathic torsion dystonia. The neurochemical mechanisms of dystonia are not well understood and pharmacological (and surgical) therapy, while helpful in some, is unsatisfactory in most patients. Recently, injections of botulinum toxin into the contracting muscles have been shown to provide effective relief for most patients with focal dystonia and other disorders characterised by involuntary muscle spasms.

Botulinum toxin, a protein with molecular weight of 140,000 daltons, is produced by the bacterium Clostridium botulinum that occasionally contaminates certain foods and wounds. $^{23}$ There are eight immunologically distinct types of $C$ botulinum, but only types $A, B$, and $E$ have been linked to human botulism. Botulism, produced by the type $A$ toxin, the most potent biological toxin known to humans, is a life-threatening illness. The toxin exerts its paralytic effect by rapidly and irreversibly binding to the presynaptic cholinergic nerve terminal where it is internalised and disrupts calcium ion influx. This interferes with the release of acetylcholine from the presynaptic terminal, causing weakness. When absorbed into the systemic circulation, the toxin may produce generalised weakness, but it has a primarily local effect when injected directly into a muscle. In 1973, Dr Alan Scott, from the Smith-Kettlewell Eye Research Foundation in San Francisco, used botulinum toxin for treatment of strabismus in primates and eight years later he reported the results of botulinum toxin treatment in humans. ${ }^{4}$ Botulinum toxin has since been tried in a variety of extraocular muscle and neurological problems..$^{5-15}$

We previously demonstrated in a doubleblind, placebo controlled trial that botulinum toxin injections provide effective relief for patients with blepharospasm and possibly other focal dystonias. ${ }^{15}$ We report the results of a long-term, prospective trial of botulinum toxin treatment in 477 patients with a variety of focal dystonias and other involuntary movements.

\section{Materials and methods}

Patients and assessments

To be included in the study, the patients must have had a disabling dystonia or hemifacial spasm despite optimum pharmacological therapy, surgery, or both. All patients gave a written informed consent approved by the Institutional Review Boards for Human Research of Baylor College of Medicine and The Methodist Hospital. After a complete neurological evaluation, the patients were videotaped according to a standard protocol. With the exception of nine patients with tardive dystonia and 18 patients with hemifacial spasm, all other patients had idiopathic dystonia. Patients with spasmodic dysphonia due to laryngeal dystonia had flexible fibreoptic video laryngoscopy to exclude vocal fold pathology and tremor. When the contracting muscles in patients with cervical dystonia could not be identified by inspection and palpation, electromyography (EMG) of the neck muscles was used to select the most appropriate muscles for injection.

The severity of dystonia and hemifacial spasm was rated on a 0 to 4 scale $(0=$ no spasm; 1 = mild, barely noticeable; $2=$ mild, 
without functional impairment; $3=$ moderate spasm, moderate functional impairment; $4=$ severe, incapacitating spasm). Furthermore, the patients were instructed to rate and record the degree of their spasm in a daily diary. ${ }^{13}$ "Latency" was defined as the interval (in days) between the injection and the first sign of improvement following the injection. "Peak effect", the maximum benefit obtained from the injection, was determined after a careful review of the patient's diary, an interview of a spouse or friends, and by the patient's own perception of response. The "peak effect" was rated on a 0 to 4 scale ( $0=$ no effect; $1=$ mild improvement; 2 = moderate improvement, but no change in function; $3=$ moderate improvement in severity and function; $4=$ marked improvement in severity and function). "Global rating" was used as a measure of overall response and was defined as the peak effect score minus one point if the injection was associated with mild or moderate complications and two points if associated with severe or disabling complications. The "maximum" duration of improvement was the number of weeks during which the patients experienced "peak effect"; "total" duration was the entire period (in weeks) after the injection during which the patients noted any improvement. The patients returned for their repeat injections about every three to six months. If patients returned before the previous injection wore off, then the total or maximum duration of benefit was considered indeterminable.

The data was entered and constantly updated in a computer database.

\section{Botulinum toxin injections}

Botulinum toxin (Oculinum), was obtained from Dr A Scott, as a freeze-dried lyophilised preparation. The vials were stored frozen $\left(-20^{\circ} \mathrm{C}\right)$ until the toxin was reconstituted with $0.9^{\circ}$ o sterile saline (without preservative)

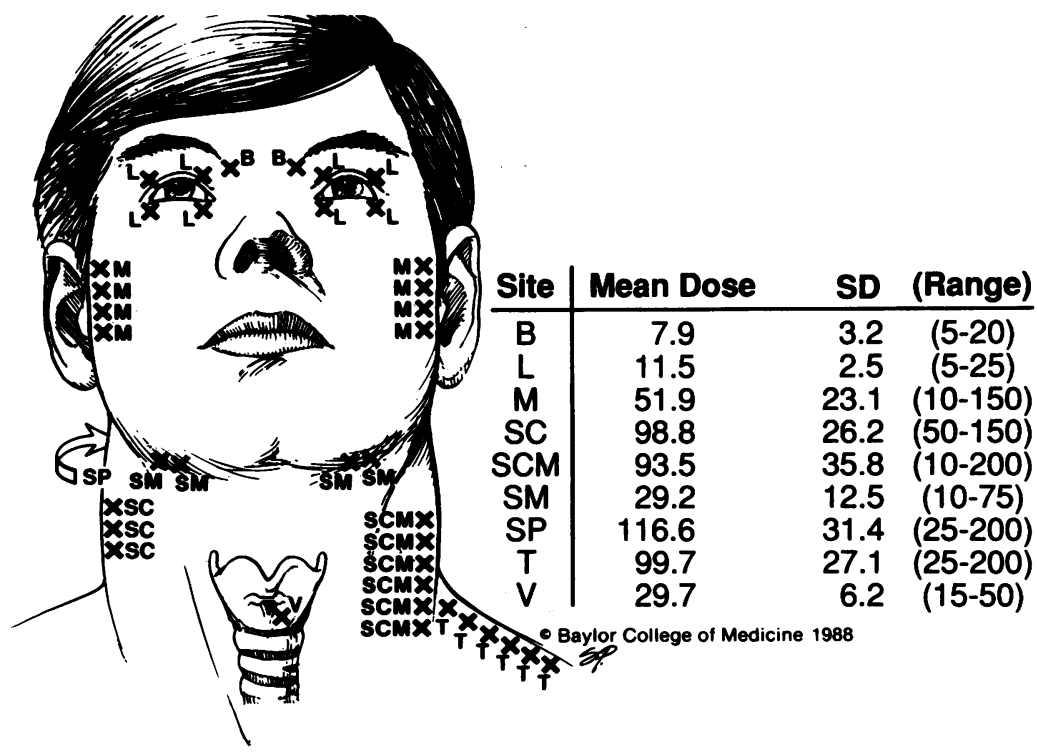

Figure 1 Botulinum toxin: location of injections and dose per muscle. $B=$ eyebrow, $L=$ eyelid (orbicularis oculi), $M=$ masseter, $S C=$ scalenus, $S C M=$ sternocleidomastoid, $S M=$ submental, $S P=$ splenius capitis, $T=$ trapezius, $V=$ vocalis complex. at the time of injection. The potency is expressed in units, where one unit (U) represents the estimated $\mathrm{LD} 50$ for mice, approximately $0.4 \mathrm{ng}$ of the protein toxin. The lethal dose in juvenile monkeys is about $40 \mathrm{U} / \mathrm{kg}$ of body weight which, when extrapolated, is approximately fifty times the average dose injected for the treatment of focal dystonia. The diluted solution was drawn into a tuberculin syringe and the toxin was injected with a 0.5 inch 30 gauge needle into superficial muscles and with a 1.5 inch 22 gauge needle into deep muscles. The dilutions were identified for each patient; $10 \mathrm{U} / 0 \cdot 1 \mathrm{ml}$ was used for small muscles such as the eyelids and vocal folds, and $20 \mathrm{U} / 0 \cdot 1 \mathrm{ml}$ was used for doses greater than $25 \mathrm{U}$ per site.

At the beginning of the study there were no published guidelines; the dose therefore for each muscle was determined empirically. Low doses were used initially, particularly for small muscles, and the dose was titrated at subsequent visits depending on the patient's response after the previous injection. As we gained more experience, we adopted the following dose schedule for initial injection: $5 \mathrm{U}$ for each eyebrow, $12.5 \mathrm{U}$ for each eyelid, $50 \mathrm{U}$ for each masseter, $20 \mathrm{U}$ for other facial muscles, $100 \mathrm{U}$ for neck or shoulder muscles, $30 \mathrm{U}$ for one vocal fold (only one vocal fold was injected in a single visit), $25 \mathrm{U}$ for forearm and $100 \mathrm{U}$ for distal leg muscles.

\section{Injection technique}

With the patient in a supine position, the eyelids and eyebrows were cleaned with alcohol and the toxin was injected medially and laterally into the pretarsal orbicularis oculi, avoiding the superior oblique and the levator palpebrae muscles to prevent diplopia and ptosis respectively (fig 1). The masseter, temporalis and submental or suprahyoid (digastric, geniohyoid, and mylohyoid) muscles were also injected when the patient was in a supine position. Other muscles were identified by palpation or by EMG and were injected with the patient in a sitting position. Patients with torticollis usually required injections into the sternocleidomastoid muscle (SCM) responsible for turning the head to the opposite side. This was usually combined with injections to the contralateral trapezius. Patients with retrocollis needed injections into both splenius capitum muscles, whereas laterocollis was treated with injections into the ipsilateral splenius capitis, trapezius, and occasionally scalenus medius. Anterocollis usually resulted from contraction of both SCMs, but occasionally injections into the submental muscles were also needed. The total dose was distributed into the larger neck muscles in four to six injections. The left thyroarytenoid vocalis muscle complex was identified by EMG and the toxin was injected through the same teflon coated hollow monopolar needle (fig 2). The posterior pharyngeal and pterygoid muscles were approached orally. ${ }^{11}$ Hemifacial spasm was treated with local injections into the muscles which contracted most, carefully avoiding perilabial regions. Patients 
Figure 2 Diagram showing injection of botulinum toxin into the left vocalis muscle complex.

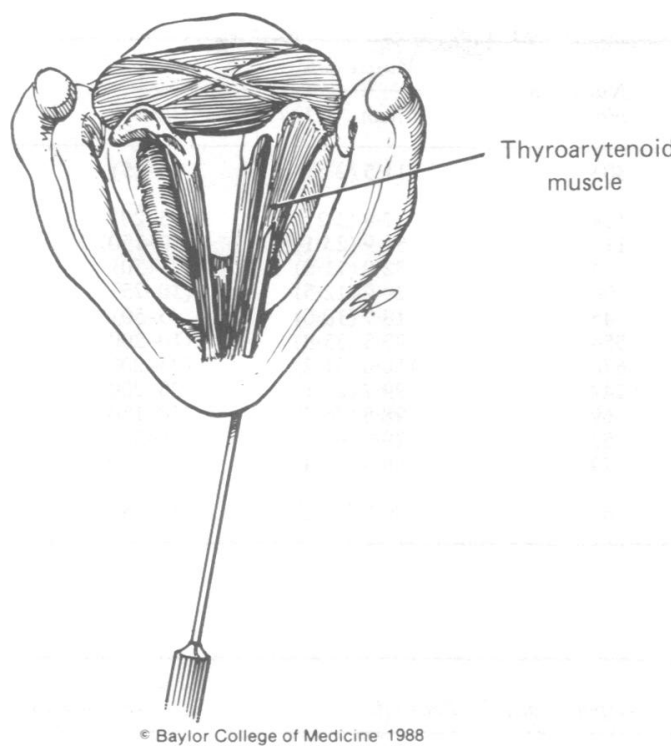

with distal focal dystonia, such as writer's cramp or foot dystonia, received injections into the most actively contracting muscles identified by palpation and occasionally, by EMG.

\section{Results}

We report the results of 3806 botulinum toxin injections in 477 patients treated in 1509 visits (tables 1-5 and fig 3). The average duraton of follow up for the 315 patients seen at more than one visit was 411 days (up to 54 months). The average number of visits per patient was $3 \cdot 0$. The mean (SD), peak effect ranged from 1.9 (1.3) for patients injected in their forearm muscles for hand dystonia to $3.6(0.8)$ for patients with blepharospasm. The duration of maximum improvement ranged from $6 \cdot 7(5 \cdot 5)$ weeks for patients with hand dystonia to $15 \cdot 1$ $(7 \cdot 2)$ weeks for patients with hemifacial spasm; but the total improvement lasted two to four weeks longer.

Only 30 patients failed to improve (global rating $\leqslant 1$ ) after one or more injections. Of the 941 evaluable visits with follow up data, 150

Table 1 Clinical features
$(16 \%)$ were unsuccessful in that patients noted only minimal or no improvement in their spasms or pain (global rating $\leqslant 1$ ). Analysis of the failures reveals that they occurred after either the first or second injection and improvement was obtained after subsequent injections using a higher dose.

In 70 of the 90 patients injected for blepharospasm who were followed up (212 visits) a favourable response (global rating $\geqslant 2$ ) was obtained in $94 \%$. The average dose per each eyelid (upper and lower) was $12 \mathrm{U}$ and per eyebrow $8 \mathrm{U}$. The response was noted an average of four days after the injection. The mean (SD) global rating of $3.5(0.9)$ indicated that botulinum toxin considerably improved disability from blepharospasm. The average maximum improvement lasted about 12 weeks, but the average total duration of benefit was longer, up to 88 weeks [mean (SD): $15 \cdot 7(9 \cdot 3)$ ]. While $87(41 \%)$ visits were followed by local or systemic complications, only five of these were disabling and all resolved in a few days. The complications included ptosis (32 visits), blurred vision or diplopia (27), tearing (21), and local haematoma (12) (table 5).

Sixty two patients with oromandibular dystonia, received a total of 407 injections in 186 visits into muscles involved with jaw and mouth opening, closure, or deviation. These included masseters (114 right and 113 left), submental (78 right and 79 left), temporalis (eight each), and pterygoids (three right and four left). Initially, we used only $25 \mathrm{U}$ per muscle, but as we gained more experience we increased the dose per masseter and temporalis muscles to $50 \mathrm{U}$. Although the "peak effect" $(2 \cdot 4)$ and the maximum response duration (7.7 weeks) of the 45 patients with follow up data in this group were less than in blepharospasm patients, $73 \%$ had a favourable response (global rating $\geqslant 2)$. Forty two of $115(37 \%)$ visits were followed by some complications, primarily consisting of dysphagia.

Twenty four patients with spasmodic dysphonia due to abnormal involuntary adduction of the vocal cords all had a very satisfactory

\begin{tabular}{|c|c|c|c|c|}
\hline \multirow[b]{2}{*}{ Diagnosis } & \multirow[b]{2}{*}{ Site of injection } & \multirow{2}{*}{$\begin{array}{l}\text { Number of patients } \\
\text { Sex }(M / F)\end{array}$} & \multicolumn{2}{|c|}{$\begin{array}{l}\text { Age } \\
\text { Age at onset } \\
\text { Duration (Yrs) }\end{array}$} \\
\hline & & & Mean (SD) & (Range) \\
\hline Blepharospasm & Lid brow & $90(22 M / 68 F)$ & $\begin{array}{c}60 \cdot 0(11 \cdot 8) \\
52 \cdot 1(12 \cdot 1) \\
6 \cdot 5(6 \cdot 6)\end{array}$ & $\begin{array}{l}(16-83) \\
(7-76) \\
(0.4-33)\end{array}$ \\
\hline Oromandibular dystonia & $\begin{array}{l}\text { Masseter Temporalis } \\
\text { Submental Pterygoid }\end{array}$ & $62(18 \mathrm{M} / 44 \mathrm{~F})$ & $\begin{array}{c}57.2(10 \cdot 9) \\
48.9(12 \cdot 1) \\
7.9(7 \cdot 2)\end{array}$ & $\begin{array}{l}(14-78) \\
(7-77) \\
(0.5-33)\end{array}$ \\
\hline Cervical & $\begin{array}{l}\text { SCM Splenius } \\
\text { Trapezius Scalenus }\end{array}$ & $303(120 \mathrm{M} / 183 \mathrm{~F})$ & $\begin{array}{r}51.8(12.1) \\
43.1(13.5) \\
9.0(10.4)\end{array}$ & $\begin{array}{l}(16-80) \\
(0.9-73) \\
(0.1-61)\end{array}$ \\
\hline Spasmodic dysphonia & Vocal fold & $24(6 \mathrm{M} / 18 \mathrm{~F})$ & $\begin{array}{c}54 \cdot 4(13 \cdot 3) \\
45 \cdot 0(12 \cdot 8) \\
9 \cdot 1(7 \cdot 6)\end{array}$ & $\begin{array}{l}(28-79) \\
(16-64) \\
(0.5-31)\end{array}$ \\
\hline Hemifacial spasm & Facial lid & $18(5 \mathrm{M} / 13 \mathrm{~F})$ & $\begin{array}{c}60 \cdot 1(8 \cdot 9) \\
54 \cdot 1(12 \cdot 3) \\
7 \cdot 1(7 \cdot 3)\end{array}$ & $\begin{array}{r}(40-75) \\
(16-73) \\
(2-33)\end{array}$ \\
\hline Hand & Extensors flexors & $28(9 M / 19 F)$ & $\begin{array}{c}42.3(15.6) \\
39.0(16.8) \\
7.9(7.9)\end{array}$ & $\begin{array}{r}(17-79) \\
(6-76) \\
(1-33)\end{array}$ \\
\hline Other focal dystonias & & $35(13 M / 22 F)$ & $\begin{array}{r}46 \cdot 6(14.4) \\
38 \cdot 6(15.0) \\
7.9(11.5)\end{array}$ & $\begin{array}{l}(15-70) \\
(0-61) \\
(0.5-67)\end{array}$ \\
\hline
\end{tabular}


Table 2 Botulinum toxin: site and dose of injections

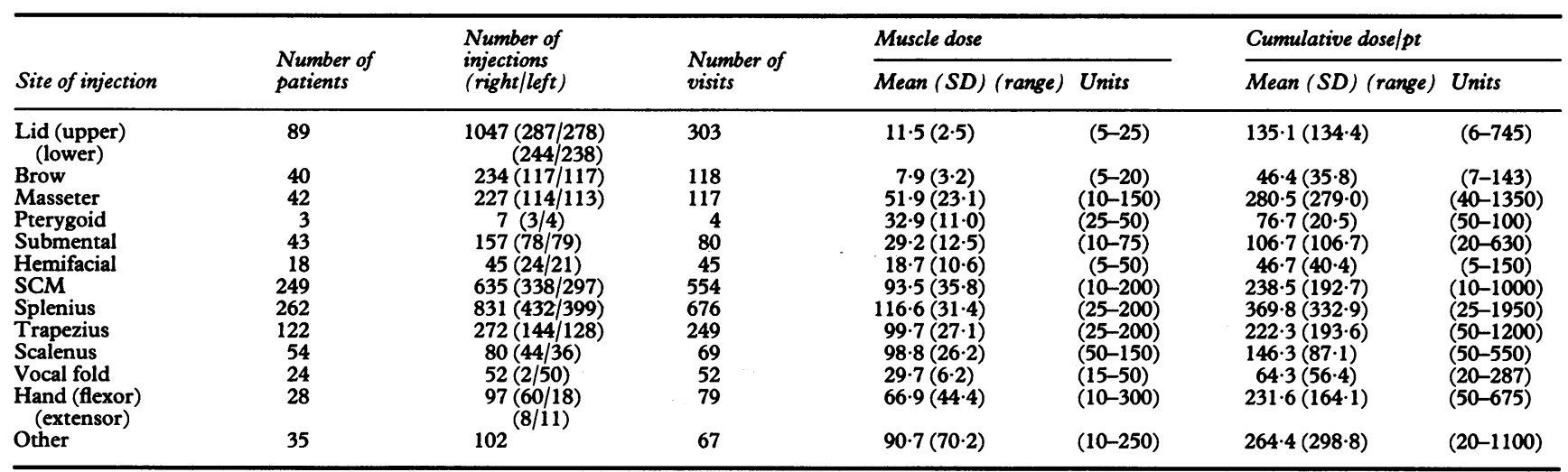

$\mathrm{SCH}=$ Sternocleidomastoid muscle.

Table 3 Response to botulinum toxin injections

\begin{tabular}{|c|c|c|c|c|c|c|c|c|c|c|c|}
\hline \multirow[b]{2}{*}{ Type of dystonia } & \multicolumn{2}{|l|}{ Global rating } & \multirow{2}{*}{$\begin{array}{l}\text { Number of } \\
\text { evaluable } \\
\text { patients| } \\
\text { visits }\end{array}$} & \multicolumn{2}{|c|}{ Latency to response (days) } & \multicolumn{2}{|l|}{ Peak effect } & \multicolumn{2}{|c|}{$\begin{array}{l}\text { Duration of response } \\
\text { (weeks) maximum }\end{array}$} & \multicolumn{2}{|l|}{ Total } \\
\hline & Mean (SD) & (Range) & & $\operatorname{Mean}(S D)$ & (Range) & Mean (SD) & (Range) & $\operatorname{Mean}(S D)$ & (Range) & $\operatorname{Mean}(S D)$ & (Range) \\
\hline $\begin{array}{l}\text { Blepharospasm } \\
\text { Oromandibular } \\
\text { Cervical } \\
\text { Spasmodic } \\
\text { dysphonia }\end{array}$ & $\begin{array}{l}3.4(0.9) \\
2.2(1.5) \\
2.9(1.2) \\
3.3(1.0)\end{array}$ & $\begin{array}{l}(0-4) \\
(0-4) \\
(0-4) \\
(0-4)\end{array}$ & $\begin{array}{c}70 / 212 \\
45 / 115 \\
195 / 500 \\
13 / 29\end{array}$ & $\begin{array}{l}4 \cdot 2(5 \cdot 7) \\
4 \cdot 6(5 \cdot 6) \\
7 \cdot 2(7 \cdot 9) \\
2 \cdot 7(3 \cdot 8)\end{array}$ & $\begin{array}{l}(0-42) \\
(0-30) \\
(0-80) \\
(0 \cdot 1-14)\end{array}$ & $\begin{array}{l}3.6(0.8) \\
2.4(1.6) \\
3.0(1.2) \\
3.4(0.8)\end{array}$ & $\begin{array}{l}(0-4) \\
(0-4) \\
(0-4) \\
(0-4)\end{array}$ & $\begin{array}{r}12 \cdot 4(8 \cdot 5) \\
7 \cdot 7(6 \cdot 4) \\
11 \cdot 7(7 \cdot 1) \\
10 \cdot 6(6 \cdot 3)\end{array}$ & $\begin{array}{l}(0-88) \\
(0-32) \\
(0-88) \\
(0-24)\end{array}$ & $\begin{array}{l}15 \cdot 7(9 \cdot 3) \\
10 \cdot 3(8 \cdot 7) \\
14 \cdot 3(7 \cdot 6) \\
14.9(8 \cdot 1)\end{array}$ & $\begin{array}{l}(0-88) \\
(0-54) \\
(0-88) \\
(0-28)\end{array}$ \\
\hline $\begin{array}{l}\text { Hemifacial } \\
\text { Hand } \\
\text { Other }\end{array}$ & $\begin{array}{l}3.1(1 \cdot 3) \\
1.5(1 \cdot 2) \\
3 \cdot 1(1 \cdot 3)\end{array}$ & $\begin{array}{l}(0-4) \\
(0-4) \\
(0-4)\end{array}$ & $\begin{array}{l}13 / 29 \\
22 / 50 \\
21 / 39\end{array}$ & $\begin{array}{l}4 \cdot 8(7 \cdot 0) \\
5 \cdot 1(5 \cdot 7) \\
6 \cdot 3(6 \cdot 3)\end{array}$ & $\begin{array}{l}(0-28) \\
(0-28) \\
(0-23)\end{array}$ & $\begin{array}{l}3.2(1.4) \\
1.9(1.3) \\
3.2(1.3)\end{array}$ & $\begin{array}{l}(0-4) \\
(0-4) \\
(0-4)\end{array}$ & $\begin{array}{c}15 \cdot 1(7 \cdot 2) \\
6 \cdot 7(5 \cdot 5) \\
9 \cdot 4(7 \cdot 6)\end{array}$ & $\begin{array}{l}(0-28) \\
(0-20) \\
(0-24)\end{array}$ & $\begin{array}{c}19.0(17.5) \\
8.6(6.9) \\
10.5(8.4)\end{array}$ & $\begin{array}{l}(0-32) \\
(0-28) \\
(0-28)\end{array}$ \\
\hline
\end{tabular}

response (global rating $\geqslant 2$ ) with average "peak effect" of 3.4. In most patients the improvement was noted within a few hours or days after injection and lasted for up to 28 weeks (average 15). The starting dose was $30 \mathrm{U}$ per one (left) vocal fold. Complications were uncommon and consisted of hypophonia or hoarseness in seven patients and dysphagia in three.

Three hundred and three patients with cervical dystonia received a total of 1818 injections in 844 visits. The muscles injected included SCM (338 right and 297 left), trapezius (144 right and 128 left), splenius capitus (432 right and 399 left), and scalenus medius (44 right and 36 left). Ninety per cent of the 195 patients with adequate follow up improved (global rating $\geqslant 2$ ). The most dramatic improvement was noted by patients who experienced pain with their cervical dystonia. Of the 123 patients who reported pain, $114(93 \%)$ noted improvement of their pain. The overall mean (SD) pain response in all patients with cervical dystonia was $3.5(1 \cdot 1)(0$ 4 scale; from $0=$ no response to $4=$ complete resolution of pain). During the last three years the average initial dose per muscle has increased from 25 to $100 \mathrm{U}$. While most patients have noted improvement within the first week after injection, a few have had a latency of up to eleven weeks. In some patients, a previously hypertrophied muscle had shrunk without improvement in the head position or range of neck movement. This usually indicated that additional muscles were involved or that the wrong muscle may have been selected. When other muscles were later injected the response usually was more favourable. Only 78 patients in 119 visits $(24 \%$ of all visits with follow up) had some complications, consisting chiefly of dysphagia (45 patients) and neck weakness (24 patients). These side effects lasted an average of 18 days.

In 18 patients with hemifacial spasm, twelve of 13 patients who had been followed up $(92 \%)$, noted reduction in unilateral blepharospasm and annoying facial twitching. The average maximum and total duration of improvement, mean 15.1 and 19.0 weeks respectively, was longer than for any of the focal dystonias (table 3). Except for transient focal weakness, seen in six of $21(21 \%)$ patients, there were no other complications.

Patients with hand dystonia (for example, writer's cramp) presented the most challenging problem because the muscles responsible for

Table 4 Botulinum toxin injections: failures and complications

\begin{tabular}{|c|c|c|c|c|c|c|}
\hline \multirow[b]{3}{*}{ Type of dystonia } & \multirow{3}{*}{$\begin{array}{l}\text { Percent of } \\
\text { patients who failed } \\
1 \text { or more visits }\end{array}$} & \multirow{3}{*}{$\begin{array}{l}\text { Percent of } \\
\text { failed visits }\end{array}$} & \multicolumn{2}{|c|}{$\begin{array}{l}\text { Number of } \\
\text { patients with } \\
\text { complications }\end{array}$} & \multirow{2}{*}{\multicolumn{2}{|c|}{ Duration in days }} \\
\hline & & & Patients & Visits & & \\
\hline & & & & (disabling) & $\operatorname{Mean}(S D)$ & (Range) \\
\hline $\begin{array}{l}\text { Blepharospasm } \\
\text { Oromandibular } \\
\text { Cervical } \\
\text { Spasmodic dysphonia } \\
\text { Hemifacial } \\
\text { Hand } \\
\text { Other }\end{array}$ & $\begin{array}{l}12 \cdot 9 \\
55 \cdot 6 \\
27 \cdot 7 \\
15 \cdot 4 \\
30 \cdot 8 \\
68 \cdot 2 \\
26 \cdot 3\end{array}$ & $\begin{array}{r}4 \cdot 7 \\
33 \cdot 0 \\
13 \cdot 2 \\
6 \cdot 9 \\
13 \cdot 8 \\
48 \cdot 0 \\
14 \cdot 7\end{array}$ & $\begin{array}{r}44 \\
28 \\
77 \\
8 \\
6 \\
6 \\
14 \\
8\end{array}$ & $\begin{array}{c}87(5) \\
42(13) \\
115(15) \\
10(1) \\
6(1) \\
22(5) \\
8(1)\end{array}$ & $\begin{array}{l}23 \cdot 8(17 \cdot 5) \\
28 \cdot 0(22 \cdot 1) \\
18 \cdot 2(14 \cdot 4) \\
29 \cdot 3(18 \cdot 7) \\
31 \cdot 8(18 \cdot 4) \\
26 \cdot 2(21 \cdot 7) \\
22 \cdot 2(16 \cdot 6)\end{array}$ & $\begin{array}{l}(2-62) \\
(2-90) \\
(0 \cdot 001-60) \\
(7-60) \\
(14-62) \\
(4-90) \\
(3-42)\end{array}$ \\
\hline
\end{tabular}


Table 5 Botulinum toxin injections: complications

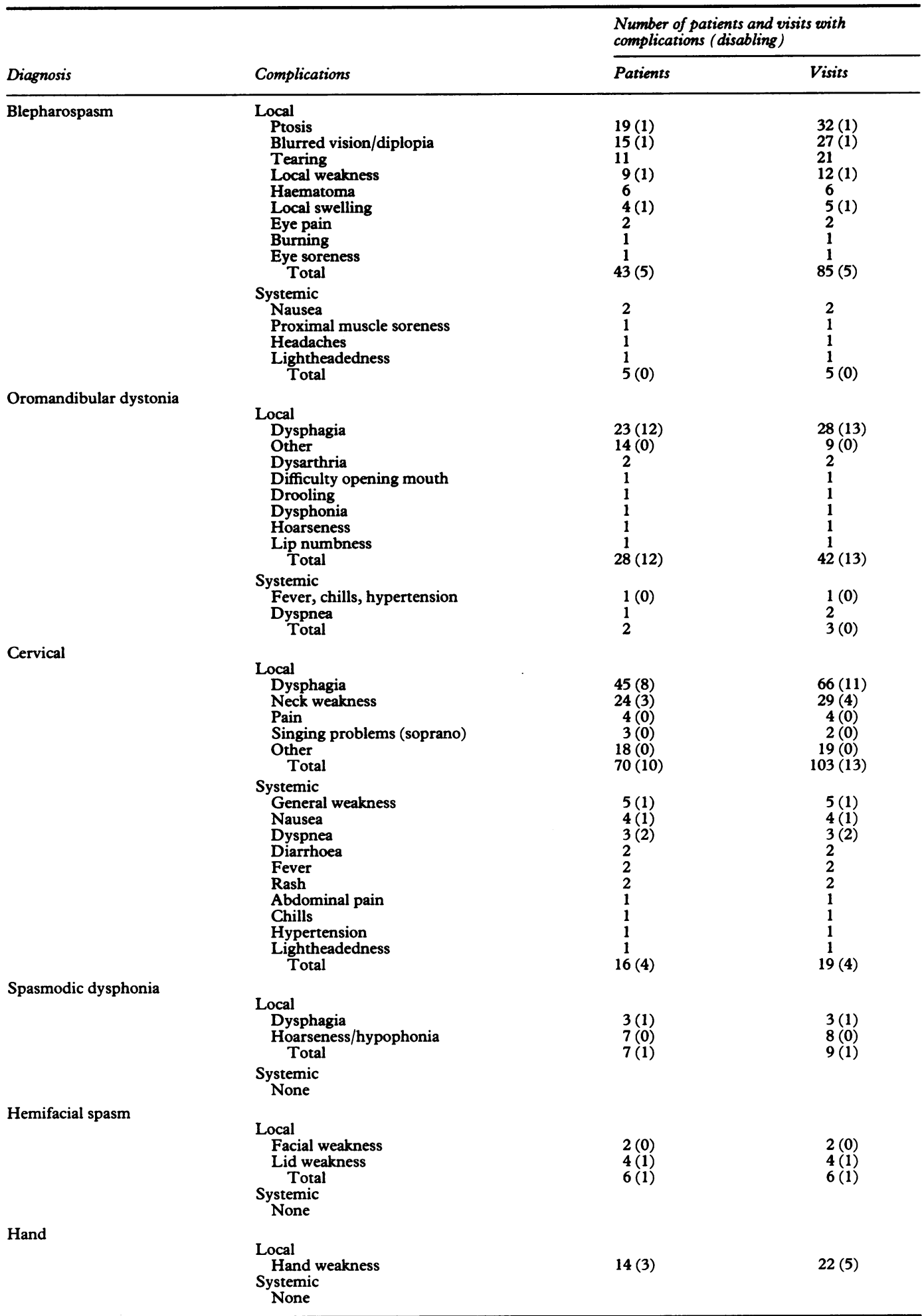

the impaired function were not always easy to identify. However, 17 of $22(77 \%)$ patients with this task-specific focal dystonia who had adequate follow up noted at least moderate (global rating $\geqslant 2$ ) improvement, although in 14 patients this was achieved at the expense of transient focal weakness. The most common site of injection was the right forearm flexors (table 2). Other sites which were injected for relief of focal dystonia include the gastrocnemius, paranasal, pectoralis, tibialis, rectus abdominus, paraspinal, and other muscles.

\section{Discussion}

This five year prospective open trial of botulinum toxin in 477 patients supports our findings from an earlier double-blind, placebo controlled study ${ }^{15}$ that botulinum toxin injections provide a safe and effective treatment for patients with focal dystonia and hemifacial spasm. Although all patients included in this study had failed to improve despite optimum pharmacological or surgical therapy, $93 \%$ noted moderate to marked relief of their spasm with botulinum toxin (fig 3). Only $16 \%$ of the 


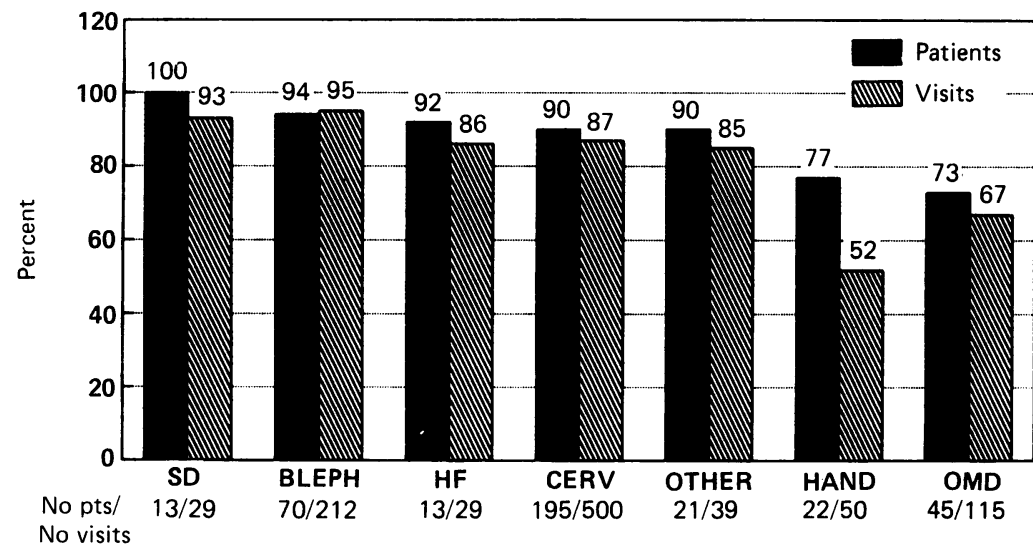

Figure 3 Percentage of patients and visits with improvement (global rating $\geqslant 2$ ) after botulinum toxin injections (botox). SD = spasmodic dysphasia,

$B L E P H=$ blepharospasm, $H F=$ hemifacial spasm, $C E R V=$ cervical dystonia, $O M D=$ oromandibular dystonia.

941 treatment visits were not successful and 43 of $94(4.6 \%)$ of all visits resulted in complications that were considered by the patients as disabling, with only one briefly admitted to hospital for dysphagia. Average duration of total improvement ranged from nine weeks in patients with hand dystonia to 19 weeks in patients with hemifacial spasm. A few maintained some improvement for over a year.

While some patients with blepharospasm obtained benefit from medications such as clonazepam, lorazepam or trihexyphenidyl and others improved after orbicularis neuromyectomy, the majority of those seen in our Movement Disorders Clinic experience disabling symptoms and some are functionally blind as a result of continuous involuntary eye closure. ${ }^{16}$ For about three months after botulinum toxin injections, almost all patients regained good visual function and some could see again for the first time in years. These patients could read, watch television, drive and function almost normally because of reduced lid and eyebrow spasms. Besides idiopathic and tardive blepharospasm, we used botulinum toxin injections successfully in two Parkinsonian patients with disabling levodopa-induced blepharospasm. One patient with progressive supranuclear palsy who had both blepharospasm and "apraxia" of eyelid opening, presumably due to inappropriate levator inhibition, noted a marked improvement in her ability to keep her eyes open for about five months after each injection. Improvement after botulinum toxin injections into the eyelids, eyebrows, and other facial muscles in patients with blepharospasm, "apraxia" of eyelid opening, and hemifacial spasm has been recognised by previous investigators. ${ }^{56}$ In this study we emphasise the value of botulinum toxin treatment not only in these disorders, but also in the treatment of other disabling dystonias.

The majority of patients with blepharospasm also have spasms in other cranial and cervical structures and cranial-cervical dystonia may occur without blepharospasm. ${ }^{17}$ Most of our patients with oromandibular dystonia were unable to chew or speak normally because of the involuntary movements and incoordination of the mouth and jaw muscles, but after botulinum toxin injections they could maintain normal nutrition and were no longer embarrassed by eating and speaking in public. However, while $73 \%$ of the patients had a satisfactory improvement (global rating $\geqslant 2$ ) in their oromandibular function, $49 \%$ experienced some complication sometime during the course of the treatment ( $37 \%$ of all visits).

Patients with spasmodic dysphonia had a particularly dramatic improvement. Because of severely strained voice, interrupted by frequent voiceless pauses, many could not communicate with their friends or relatives. However, in some instances, within hours after botulinum toxin injection, their voice improved so that they could be easily understood even when speaking on a telephone. Using bilateral injections of small doses $(2 \cdot 5-$ $3.75 \mathrm{U}$ ) of the toxin, Brin et al ${ }^{13}$ reported improvement in all 42 patients with spasmodic dysphonia. The improvement (SD), was rated as $61 \cdot 1(4 \cdot 6) \%$, lasted $84 \cdot 4(9 \cdot 3)$ days and was associated with transient breathy hypophonia in $45 \%$ and dysphagia in $22 \%$ of all treated patients.

After botulinum toxin treatment, $93 \%$ of all patients with painful cervical dystonia were no longer anguished by pain. Ninety per cent noted improvement in their head position and control. However, some patients with dystonic head/neck tremor continued to have spasmodic head movements when they volitionally turned their head against the direction of the dystonic contraction. In three patients with essential head tremor, botulinum toxin injections into both splenius capitum muscles considerably improved the head oscillation for about four months. Despite relatively large doses of the toxin (average $209 \mathrm{U}$ per visit for all cervical muscles, maximum cumulative dose $2,350 \mathrm{U}$ ) in this group of patients with cervical dystonia, only $24 \%$ of all visits resulted in some side effects, such as dysphagia or neck weakness (table 5)

One of the most promising applications for botulinum toxin injections is in the treatment of task-specific focal dystonias, often referred to as occupational cramps. ${ }^{18}$ These hand dystonias are usually quite disabling and resistant to pharmacological therapy. While only $77 \%$ of our patients improved for an average of only nine weeks, these patients were generally very appreciative because the injections enabled them to write or type, helping them to remain employed as a result of the injections. The response in these 22 patients was similar to that reported by Cohen et al. ${ }^{19}$ They felt that identification of the affected muscles by EMG was necessary for a favourable outcome. Sixteen of their 19 patients benefited from the injections for one to six months, but (like our patients), the improvement often occurred at the expense of transient weakness.

Our experience in 13 patients with hemifacial spasm indicates that botulinum toxin injections should now be considered the treatment of choice for this form of segmental myoclonus. Ninety two per cent of the patients improved and the improvement in this group lasted longer (mean maximum improvement 15 weeks, total 19 weeks) than in focal dystonia. 
One possible reason for this long duration of improvement may be the presence of subclinical denervation, which may also account for the lower than usual dose needed for the treatment of unilateral blepharospasm associated with the hemifacial spasm. Because of the marked benefit from botulinum toxin injections, we no longer recommend microvascular facial nerve decompression for these patients except in rare cases.

A detailed analysis of 30 patients who failed to improve even after several treatment visits did not reveal any clinical variables, such as age, duration of illness, previous history of surgical treatment or any other demographic data that could reliably predict the poor outcome. One possible explanation for the failure to improve after botulinum toxin injections is the presence of blocking antibodies, either as a result of previous injections or because of a previous history of botulism. While some investigators $^{718}$ have found anti-botulinum toxin antibodies, particularly in those patients who have received large cumulative doses and who failed to respond, another study ${ }^{20}$ found no antibodies by either bioassay or immunoassay in a large group of patients treated with the toxin. Furthermore, the presence of blocking antibodies would not explain why, despite marked weakness and atrophy of the injected muscle, some patients fail to improve. We suspect that, in such cases, the abnormal dystonic movement or posture is due to contractions of muscles that were not injected or were not readily accessible. Another possible reason for poor response to botulinum toxin injections is the presence of secondary contractures or skeletal deformities.

Besides the development of antibodies, other potential concerns on the effects of repeated botulinum toxin injections include local spread of injectate (which could account for some of the complications due to weakness of adjacent muscles), retrograde transport of the toxin with eventual involvement of the spinal cord or brainstem, and the possibility of denervation supersensitivity. ${ }^{21} 22$ To prevent effects of local diffusion, some investigators have suggested that the toxin should be injected as close to the motor end-point as possible. In one study, patients with blepharospasm were injected only in motor end-points identified by percutaneous electrical stimulation (lateral periorbital region of the upper eyelid and medial preseptal region of the lower eyelid) [G Borodic, personal communication]. The response was not as good as when the toxin was administered by multiple injections over the length of the muscle. One possible explanation is that motor end-point, as identified by a cutaneous stimulus, may not be near the actual neuromuscular junction. We obtained good results by distributing the injections near the midpoint of the muscle, an area which presumably contains the innervation zone. We did not see the need to use EMG to identify motor end-points. While some investigators using single fibre EMG recordings have suggested that the toxin might have a systemic action, ${ }^{2324}$ there is so far no evidence that repeat injections of the toxin produce any serious adverse systemic effects.

Although there are many unanswered questions about this new therapy, our results suggest that botulinum toxin injection should now be regarded as the treatment of choice for disabling focal dystonia and hemifacial spasm. While the long-term effects of repeated injections of botulinum toxin are unknown, our experience indicates that the treatment is safe and that the beneficial effects seem to be maintained for at least five years.

We thank Compaq Computer Corporation for donating the computer equipment used in the analysis of the data presented.

1 Jankovic J, Fahn S: Dystonic syndromes. In: Jankovic J, Tolosa E, eds. Parkinson's disease and movement disorders, 283-314.

2 Sellin LC. The action of botulinum toxin at the neuromuscular junction. Med Biol 1981;59:11-20.

3 Dolly JO, Black J, Williams RS, Melling J. Acceptors for botulinum neurotoxin reside on motor nerve terminals and mediate its internalization, Nature 1984;307:457-60.

4 Scott AB. Botulinum toxin injection of eye muscles to correct strabismus. Trans Am Ophthalmol Soc 1981;79:734-70.

5 Scott AB, Kennedy RA, Stubbs HA. Botulinum A Toxin injection as a treatment for blepharospasm. Arch Ophthalmol 1985;103:347-50.

$6 \mathrm{Katz} \mathrm{B}$, Rosenberg JH. Botulinum therapy for apraxia of eyelid opening. Am J Ophthalm 1987;103:718-9.

7 Brin MF, Fahn S, Moskowitz CB, et al. Localized injections of botulinum toxin for the treatment of focal dystonia and of botulinum toxin for the treatment of focal dystonia and

8 Tsui JKC, Calne DB. Botulinum toxin in cervical dystonia. In: Jankovic J, Tolosa E (eds), Facial Dyskinesias, Adv Neurol, Vol 49, New York, NY: Raven Press, 1988 479-92.

9 Stell R, Thompson PD, Marsden CD. Botulinum toxin in spasmodic torticollis. J Neurol Neurosurg Psychiatry 1988;51:920-3.

10 Jankovic J, Schwartz K. Botulinum toxin injection for cervical dystonia. Neurology 1990;40:277-80.

11 Miller RH, Woodson GE, Jankovic J. Botulinum toxin injection of the vocal fold for spasmodic dysphonia. A preliminary report. Arch Otolaryngol Head Neck Surg preliminary report.

12 Ludlow CL, Naunton RF, Sedory SE, Schulz GM, Hallett $M$. Effects of botulinum toxin injections on speech in adductor spasmodic dysphonia. Neurology 1988;38: 1220-5.

13 Brin MF, Blitzer A, Fahn S, et al. Adductor laryngeal dystonia (spastic dysphonia): Treatment with local injections of botulinum toxin (botox). Movement Disorders 1989;4:287-96.

14 Cohen LG, Hallett M, Geller B, Hochberg F. Treatment of focal dystonias of the hand with botulinum toxin injections. J Neurol Neurosurg Psychiatry 1989;52:355-63.

15 Jankovic J, Orman J. Botulinum A toxin for cranial-cervical dystonia: A double-blind, placebo-controlled study. Neurology 1987;37:616-23.

16 Jankovic J, Ford J. Blepharospasm and orofacial-cervical dystonia: Clinical and pharmacologic findings in 100 dystonia: Clinical and pharmacologic

17 Jankovic J. Etiology and differential diagnosis of blepharospasm and oromandibular dystonia. In: Jankovic J, Tolosa E, eds. Facial Dyskinesias, Adv Neurol, Vol 49. New York, NY: Raven Press, 1988:103-16.

18 Rosenbaum F, Jankovic J. Task-specific focal dystonia and tremor: Categorization of occupational movement disorders. Neurology 1988;38:522-7.

19 Tsui JK, Wong NLM, Wong E, Calne DB. Production of circulating antibodies to botulinum-A toxin in patients receiving repeated injections for dystonia. Ann Neurol 1988;23:181 (abstract).

20 Biglan AW, Gonnering R, Lockhart LB, Rabin B, Fuerste FH. Absence of antibody production in patients treated with botulinum A toxin. Am J Ophthalmol 1986;101: with 5 .

21 Wiegand H, Erdmann G, Wellhoner HH. ${ }^{125} I$-labelled botulinum A neurotoxin: pharmacokinetics in cats after botulinum A neurotoxin: pharmacokinetics in cats after intramuscular injection. Narmacol 1976;292:161-5.

22 Black JD, Dolly JO. Interaction of ${ }^{125} \mathrm{I}$-labelled botulinum neurotoxins with nerve terminals. I: Ultrastructura autoradiographic localization and quantitation of distinct membrane receptors for types $A$ and $B$ on motorneurons. $J$ Cell Biol 1986;103:521-34.

23 Lange DJ, Brin MF, Warner CL, Fahn S, Lovelace RE. Distant effects of local injections of botulinum toxin. Muscle and Nerve 1987;10:552-5.

24 Sanders DB, Massey EW, Buckley EC. Botulinum toxin for blepharospasm: Single-fiber EMG studies. Neurology 1986;36:545-7. 